\title{
A crise da Covid-19 e o sistema mundo: perspectivas sobre epidemias na história e desigualdades globais
}

\author{
The Covid-19 crisis and the world system: perspectives on \\ epidemics in history and global inequalities
}

\author{
La crisis de la Covid-19 y el sistema mundo: perspectivas \\ sobre las epidemias en la historia y las \\ desigualdades globales
}

\section{Rodrigo Cantu}

Professor do Departamento de Sociologia e Política e do Programa de Pós-Graduação em Sociologia da Universidade Federal de Pelotas, RS, Brasil. Graduado em Ciências Econômicas pela UFPR, mestre em Sociologia pelo IUPERJ e doutor em Sociologia pelo IESP-UERJ. E-mail: rodrigo.cantu@ufpel.edu.br

\section{Resumo}

O artigo aponta lições da teoria do sistema mundo sobre alguns aspectos da crise ensejada pela pandemia de covid-19. Com base em material jornalístico, relatórios de organismos internacionais, dados estatísticos do contexto de 2020 e realizando uma análise bibliográfica da referida constelação teórica, propõem-se três ensinamentos sobre a experiência global de um ano de pandemia. Primeiro, a pandemia deve ser entendida como um fenômeno endógeno à dinâmica do sistema-mundo capitalista. Segundo, a desigualdade global deve ser um quadro de referência indispensável para o exame das diferentes experiências engendradas pela pandemia. Finalmente, a disputa por hegemonia organiza alguns dos principais contenciosos da conjuntura, tais como a rivalidade em torno da adoção de distintas vacinas.

Palavras-chave: teoria do sistema mundo; Covid-19; história; epidemias. 


\section{Introdução}

A classificação pela Organização Mundial da Saúde (OMS) dos surtos de covid-19 como pandemia em março de 2020 e a crise econômica associada à expansão da doença instaram diferentes campos de conhecimento ao estudo desse momento de ruptura. Um conjunto de publicações mostra como cientistas sociais e sociólogos se mobilizaram rapidamente, no Brasil e no mundo, para refletir sobre o novo fenômeno e a conjuntura (Matthewman; Huppatz, 2020; Rodrigues; Costa; Guedes, 2020; Delanty, 2021; Pieterse; Lim; Khondker, 2021; Reflexões na Pandemia, Revista Dilemas). O presente artigo se junta a esses esforços, com o objetivo de lançar luz sobre a experiência de um ano de pandemia. Seguimos a convocação de Pleyers (2021), para a elaboração de uma sociologia global dos tempos do coronavírus. Mobilizamos ferramentas teóricas da sociologia a fim de analisar a vivencia das pessoas e o episódio da pandemia no quadro da dinâmica de estruturas sociais dilatadas espacial e temporalmente.

O texto busca explorar algumas contribuições das teorias do sistema mundo, a fim de situar a pandemia de covid-19 na longa relação entre sociedades, seus espaços e epidemias ${ }^{1}$. Ao colocar a questão em uma perspectiva histórica e sociológica abrangente, essas literaturas moderam a percepção de ineditismo e nos recordam da recorrente repercussão das doenças no desenvolvimento das sociedades. Epidemias manifestam a extensão das relações humanas e algumas de suas principais dinâmicas, impulsionando transformações de larga escala na antiguidade, precipitando o surgimento da modernidade e, como sugere a crise do coronavírus, suscitando novas indeterminações e possíveis mudanças no mundo contemporâneo. Salientamos três lições dessa perspectiva teórica para o contexto presente. Primeiro, a pandemia deve ser entendida como um fenômeno endógeno à dinâmica de um sistema mundo capitalista. Segundo, a desigualdade global deve ser um quadro de referência indispensável para o exame das diferentes experiências engendradas pela pandemia. Finalmente, a disputa por hegemonia organiza alguns dos principais contenciosos da conjuntura, tais como a rivalidade em torno da adoção de distintas vacinas.

O restante do texto está organizado em mais quatro seções. Na primeira, examinamos alguns aspectos do primeiro ano de pandemia em diferentes contextos regionais. Inserimos essas

\footnotetext{
${ }^{1}$ Para uma introdução aos princípios dessas correntes, ver Arenti e Filomeno (2007) e Vieira, Vieira e Filomeno (2012). Ao longo do texto, usamos o termo sistema mundo, sem hífen, sugerindo a preferência pela formulação continuísta de Frank e Gills (1993) e Chase-Dunn e Hall (1997). Ela é mais apropriada para o exame do papel de epidemias trans-historicamente. Nessa perspectiva, haveria uma unificação das comunidades humanas desde pelo menos o segundo milénio Antes da Era Comum e esse sistema mundo precocemente unificado estaria sujeito às propriedades básicas do sistema social moderno (tais como divisão centro-periferia, rivalidade e hegemonia, etc.). A perspectiva alternativa de Wallerstein (1993) sustenta que há uma ruptura histórica no mundo moderno, enfatizando o ineditismo de um sistema planetário. Por essa razão, Wallerstein reforça a importância do hífen no termo sistemamundo. Antes do sistema planetário, existiriam sistemas-mundo, no plural.
} 
realidades na discussão sobre política social, subsistência e segurança em países periféricos. Em seguida, elaboramos alguns pontos essenciais da abordagem teórica que orienta o argumento, a perspectiva continuísta da teoria do sistema mundo. Na terceira seção, discutimos o papel de doenças e epidemias na dinâmica social. Por último, retomamos algumas das contribuições da teoria do sistema mundo para a compreensão dos tempos de coronavírus.

\section{As experiências da pandemia}

Como examinar a experiência de um ano de pandemia? Em um recorte certamente parcial, recorremos a dados estatísticos, informações de relatórios, relatos de vida publicados pela imprensa e por organismos internacionais, além de eventos marcantes noticiados. Enfocamos diferentes dimensões, de experiências locais ao jogo geopolítico internacional, evidenciando como a pandemia afetou as populações de maneira desigual, sublinhando diferenças entre regiões do planeta. O intuito é apresentar alguns aspectos do ano pandêmico para alimentar a reflexão de longa duração do sistema mundo sobre a conjuntura presente.

Relatórios de organismos internacionais, dados de institutos de estatísticas e resultados de pesquisas acadêmicas desenham um período de crise econômica e emocional. O PIB mundial caiu 3,3\% em 2020, com efeitos desiguais ao redor do globo. As projeções do FMI (2021) sugerem que a queda no PIB per capita no período 2020-2022 no sul global deve ser de 20\%, em comparação com 11\% no norte global. A OIT estima que, em 2020, 255 milhões de empregos a tempo integral desapareceram no planeta (ILO, 2021). Novamente, a incidência dos efeitos perversos da desarticulação econômica e do desemprego é bastante desigual, atingindo trabalhadores com baixa qualificação e baixa remuneração. Os países de renda média-baixa foram os mais afetados, com destaque para a grande perda de empregos comparativamente na América Latina. Em contraste com outro evento marcante desta geração, a destruição de empregos foi quatro vezes maior que durante a crise subprime de 2008-2009 (ILO, 2021:5-8). Associadas à ruptura das formas de subsistência, ansiedade e outras formas de sofrimento psíquico acometeram uma proporção muito maior da população mundial ao longo de 2020 (Castaldelli-Maia et al., 2021; Wang et al., 2020; Aknin et al., 2021).

Diferentes experiências subjacentes a esses números podem ser ilustradas pelos casos relatados por uma notícia do Banco Mundial (2021). Imbuído de seu costumeiro comprometimento com soluções que promovam arranjos de mercado e empreendedorismo, o organismo descreve, por exemplo, a vivência de um artesão de um vilarejo turístico no Laos, cujo negócio foi duramente golpeado pela pandemia. Sem os turistas estrangeiros, a receita caiu 
e ele precisou dispensar alguns ajudantes. A notícia salienta ainda que, há alguns anos atrás, não havia acesso à capital de giro para autônomos e pequenos empresários, como o aludido artesão laosiano, via bancos no país. Com ajuda de um programa do Banco Mundial, foram criadas linhas de crédito para estimular as atividades desses atores econômicos. Outro exemplo na África, narra o caso de um programa de melhorias em favelas do Quênia. "Como jovens de Kibera, somos muito gratos ao governo por lançar este programa, porque não só nos permite cuidar de nossas famílias e pagar nossas contas, mas também garante que os jovens não fiquem ociosos [...], o que minimizou significativamente os índices de criminalidade em nossa área”, comemora um líder comunitário da maior favela de Nairobi. Também afetados por restrições à mobilidade impostas por conta do coronavírus, os moradores dessas localidades encontraram algum alívio econômico no programa, que é financiado pelo Banco Mundial e outras agências europeias de ajuda internacional.

No Reino Unido, o caso de Jo Aitken, apresentado pela BBC (18/02/2021) em uma galeria de vivências na pandemia, complementa esse quadro. Aitken trabalhava como parteira comunitária do sistema público universal de saúde (NHS) e, com sequelas do covid-19 desde junho de 2020, se encontrava afastada de suas atividades laborais. "Tenho recebido cuidados muito bons do NHS ultimamente, e também do meu empregador", conta a inglesa, se referindo provavelmente a uma empresa terceirizada, contratada pelo NHS para realizar os serviços obstétricos. Seu caso é comentado à luz da iniciativa de alguns parlamentares, que buscam incluir o covid-19 no rol de doenças ocupacionais do setor de saúde, garantido uma eventual compensação para os trabalhadores da área.

Essas experiências podem ser entendidas à luz de uma literatura que, embora centrada no tema das políticas sociais, evidencia também as formas segundo as quais as pessoas lidam com diferentes riscos a existência (climáticos, sanitários, sociais, econômicos, do ciclo de vida etc.). Embora essa abordagem seja subjacente a clássicos dessa área - por exemplo, nos regimes de estado de bem-estar de Esping-Andersen (1990) -, ela aparece explícita em formulações mais recentes, entre as quais se destacam trabalhos de autores latino-americanos (Cf. Cecchini et al., 2015). A contribuição de Gough et al. (2004) arremata as bases dessa perspectiva, ao entender a ideia de regimes de estado de bem-estar, propondo em seu lugar regimes de subsistência (ou de segurança). Para dar conta das diferentes fontes de insegurança em países do sul global, expande-se a matriz institucional à qual as pessoas recorrem para se proteger contra riscos diversos, que, nos países estudados por Esping-Andersen, podem ser reduzidos a família, mercado e estado. 
A pandemia de covid-19 é um choque, uma ampliação súbita dos riscos sanitários, que enseja diferentes experiências de acordo com os distintos regimes de subsistência. Em algumas regiões, estado e mercado são robustos e exercem um papel importante na superação da indeterminação vivida. A britânica Jo Aitken, por exemplo, habita em um contexto no qual o mercado é uma instância relevante e efetiva. Como cerca de $85 \%$ da população ocupada no Reino Unido ${ }^{2}$, ela é uma trabalhadora assalariada: há um mercado de trabalho constituído, no qual as pessoas conseguem sua subsistência trabalhando em organizações que utilizam métodos e tecnologias avançadas. O estado também assume responsabilidades comparativamente amplas, oferecendo à parteira não apenas o tratamento de saúde pelo sistema público (que também a emprega), mas também auxílio de renda durante seu afastamento do trabalho. Para ela, a família tem um papel subsidiário nessa crise. Talvez o parentesco seja relevante se conjecturarmos, por exemplo, que sua irmã veio morar com ela depois de perder o emprego. Um desfecho de familiarização do sustento na pandemia que é possível, mas talvez menos provável, dado que o governo britânico instituiu um plano de auxílio à trabalhadores em empresas desde o início de 2020.

Nos outros dois contextos, o quadro institucional é bastante distinto. O mercado, por exemplo, é uma instância menos vigorosa. Menos de 1/3 da população ocupada é assalariada no Laos e no Quênia: são menos presentes empresas usuárias de modernos métodos e tecnologias, que precisam recrutar mão de obra assalariada. Podemos conjecturar que o jovem líder comunitário queniano é um trabalhador por conta própria, fazendo bicos ou tocando um micronegócio, como 2/3 das pessoas ocupadas no país. Se ele adoecer de covid, talvez a qualidade de seu tratamento não seja a mesma dispensada à parteira britânica, visto que o gasto público per capita com saúde é quase dez vezes maior no Reino Unido ${ }^{3}$. O abalo sanitário e econômico ressalta a fragilidade comparativa do estado e do mercado no Quênia. Não há seguro desemprego ${ }^{4}$ e, durante a pandemia, um auxílio especial só foi instituído em abril de 2021 . Não apenas a família e a comunidade se tornam então instâncias relevantes para a proteção e o sustento, mas também a ajuda internacional, como sugere o programa de empregos financiado pelo Banco Mundial e parceiros. Essa maior variedade da matriz institucional à qual as pessoas recorrem também é ilustrada no caso do artesão laosiano. Na crise, o apoio internacional entra para fortalecer instrumentos de mercado, com linhas de crédito não proporcionadas por entidades financeiras domésticas.

\footnotetext{
${ }^{2}$ Segundo dados do Banco Mundial.

${ }^{3}$ Segundo dados da OMS.

${ }^{4}$ Ver ILO (2017).
} 
Em resumo, as experiências humanas em um ano de pandemia são moldadas pela variedade de regimes de subsistência existentes. Em alguns contextos, a crise sanitária e econômica encontrou instituições estatais e mercados desenvolvidos. Em outros, menores capacidades estatais, mercados vacilantes e baixa disseminação tecnológica ${ }^{5}$ ensejam a maior importância da família, comunidade, ajuda internacional e migração (sustento com remessas de parentes, por exemplo). A vulnerabilidade humana é função da densidade dessa rede institucional na proteção contra a crise e a indeterminação.

Seguindo propostas como as de Wolf (2005) e Bhambra (2014), para dar sentido a esse conjunto de experiências, é preciso conectá-las. Em oposição ao nacionalismo metodológico que ainda vigora em rincões das ciências sociais, inseri-las em um sistema de relações planetárias revela questões e conjunturas instigantes, cujo mérito deve ser avaliado pelo leitor ${ }^{6}$. As assimetrias entre o contexto britânico e queniano, por exemplo, podem ser preliminarmente conceitualizadas por meio da imagem proposta por Cardoso: diferentes posições em uma galáxia, com um centro mais denso, um buraco negro.

\begin{abstract}
Quanto mais distantes do centro da galáxia, [...] mais rarefeitos alguns de seus mecanismos de coordenação, sobretudo a institucionalidade estatal. Mas o mercado e a informação também são mais rarefeitos. É menos denso o conjunto de instituições, o montante de recursos circulando, a qualidade da informação disponível aos agentes. Mas esses três elementos estão ali. Isso quer dizer que esses lugares distantes são parte da galáxia, sofrem a influência do centro, têm seu movimento e sua densidade determinados, justamente, pela distância em relação ao centro e, portanto, definem-se por essa relação distante (Cardoso, 2013:23).
\end{abstract}

Enquanto isso, no Brasil, 2021 começa com uma taxa de desemprego de 14,2\% em uma posição intermediária da "galáxia", com condição institucional menos rarefeita que no Quênia e no Laos, mas menos densa que no Reino Unido. Comparativamente, 2/3 das pessoas ocupadas eram assalariadas, sugerindo alguma cobertura de seguridade social no início da pandemia ${ }^{8}$. Além disso, esses assalariados, em princípio, seriam o grupo elegível aos programas de complemento salarial e redução de jornada de diferentes esferas de governo. Para os desempregados e trabalhadores por conta própria (ou outros 1/3) cuja renda foi afetada pela crise, o congresso criou o auxílio emergencial de abril a dezembro de 2020. Nesse cenário, podese conjecturar que a familiarização do sustento e dos cuidados é uma alternativa saliente.

A trama brasileira ainda foi marcada, como em outros países, pela expectativa com relação à vacina. Ao contrário de vários países que coordenaram medidas com bases científicas,

\footnotetext{
${ }^{5}$ Sobre o papel da disseminação da tecnologia no tecido produtivo e seus impactos em termos da desigualdade de produtividade e de riqueza, ver Bielschowsky e Torres (2018).

${ }^{6}$ Sobre a posição do nacionalismo metodológico no cânone da teoria social, ver Chernilo (2008).

${ }^{7} \mathrm{De}$ acordo com dados da PNAD Contínua do IBGE.

${ }^{8}$ Segundo dados do Banco Mundial.
} 
o governo federal de extrema-direita, em uma gestão confusa da pandemia, motivou no início de 2021 o episódio conhecido como "guerra das vacinas". Depois de desastradas tratativas para adquirir a vacina, as instâncias federais entraram em confronto e competição com estados, principalmente São Paulo. Em meio às disputas e controvérsias sobre a vacina e sua logística, chama atenção a rejeição da vacina chinesa por parte do presidente da república em outubro de 2020, logo depois de avanços em negociações do ministério da saúde do mesmo governo com a China. O exame do viés sinofóbico na decisão da presidência da república não pode ignorar que as decisões de governos sobre vacinas acontecem sobre um terreno de disputas geopolíticas renovadas. Secundarizando os esforços da OMS para a articulação de um consorcio de vacina global, alguns países se lançaram na corrida pelo desenvolvimento do imunizante, a fim de manobra-lo como instrumento de soft power. Na clivagem recente entre EUA e China, a vacina emerge como um novo contencioso.

Uma parte relevante, portanto, da vivência de um ano de pandemia pode ser entendida pelas dinâmicas instauradas pela crise sanitária e econômica em um mundo muito desigual, marcado por distintos regimes de subsistência e por disputas geopolíticas por hegemonia. A teoria da longa duração do sistema mundo oferece perspectivas fecundas sobre essas questões e marcos para nos orientarmos em meio a indeterminação da conjuntura pandêmica. Na seção seguinte, discutimos alguns elementos básicos dessa abordagem.

\section{O sistema mundo na longa duração}

A imagem da galáxia, aludida anteriormente, se refere vagamente a alguns termos da perspectiva da teoria do sistema-mundo. Essa formulação começa a ganhar forma com o trabalho de Wallerstein (1974a, 1974b), no qual se integram a preocupação sócio-histórica com a formação da modernidade dominada pela Europa e a dinâmica - também central nos trabalhos de cepalinos e dependentistas - de uma divisão do trabalho internacional assimétrica. No argumento base de Wallerstein, a modernidade é caracterizada por uma integração produtiva global centrada no Atlântico Norte que se desenvolve nos últimos 500 anos: um sistema-mundo planetário capitalista. Abu-Lughod (1989) sugere que tal sistema-mundo moderno seria a renovação de um sistema anterior ligando a Europa à Ásia, com auge nos séculos XIII e XIV, cuja base seria não uma integração produtiva, mas comercial. Expandindo essa intuição, Frank e Gills (1993a) propõe uma radicalização do uso do ferramental sistema mundo, defendendo que essa noção pode ser aplicada para entender a história social até o neolítico. Esse ponto é objeto de uma controvérsia dentro dessa constelação teórica, conhecido como o debate continuísta- 
transformacionista (Hall; Chase-Dunn, 1993; Straussfogel, 1998; Dudbridge, 2018; Erra, 2020). Iniciada na publicação organizada por Frank e Gills (1993b), essa divisão opõe, de um lado, esses dois autores, patrocinando a posição continuísta e, de outro lado, Wallerstein e Amin sustentando a posição transformacionista. A transformação, aqui, se refere à admissão de que somente com a consolidação de um sistema-mundo moderno se pode falar efetivamente de uma formação social capitalista, planetária e integrada. Haveria, assim, uma ruptura a partir do século XVI, que é contestada pela posição continuísta.

Há alguns aspectos dessa divisão que merecem atenção. Enquanto Wallerstein vê o cenário pré-moderno definido pela existência de impérios e sistemas sociais isolados, Frank e Gills o enxergam como a contínua formação de um único sistema mundo. Uma das bases da divergência se encontra no modo de produção. Wallerstein defende que a forma de produção capitalista, segundo uma divisão do trabalho internacional, é um elemento distintivo do moderno sistema-mundo. De modo similar a Abu-Lughod (1989), Frank e Gills admitem que um sistema social pode ser composto também por relações comerciais, além de outros laços, tais como político-militares e culturais. É uma mudança relevante nos termos teóricos antes postos por essa constelação. A posição continuísta flexibiliza a premissa materialista de Wallerstein e incorpora outras forças na definição da dinâmica social. Reformulada dessa maneira, uma história de longa duração do sistema-mundo propõe que a dinâmica regional de certo grupo social é em alguma medida determinada por relações com outros grupos, sejam em bases econômicas, políticas ou culturais.

Cabe algumas breves considerações metateóricas sobre a constelação da teoria do sistema-mundo. Ela tende a ser encarada como uma formulação exclusivamente macro, que examina aspectos sociais estruturais e de longa duração. Não obstante, Chase-Dunn e Lerro (2016) buscam também integrar as dilatadas formações sócio-históricas o exame de temas normalmente relacionados a abordagens fenomenológicas, interacionistas e etnometodológicas, como interiorização de habilidades sociais, formação do self e ordenamento (e ruptura) de situações. Isso sugere que a teoria do sistema mundo de longa duração tem uma ênfase estrutural apenas como recurso metodológico. Seria uma "análise institucional", no sentido de Giddens (1979:80-95), que coloca entre parênteses a dimensão acontecimental da ação para poder investigar os detalhes dessa dimensão da realidade social que é suprasituacional e estendida no tempo - ciente que sua realização se dá apenas na prática situada.

O restante da reflexão aqui proposta se apoia na elaboração que Chase-Dunn e Hall (1997), e principalmente Chase-Dunn e Lerro (2016), realizam de alguns termos desse debate, buscando uma síntese, mas decisivamente de inclinação continuísta. Discutem-se três aspectos 
base dessa abordagem, de uma lista mais abrangente proposta por Frank e Gills (1993a): uma definição de sistema social com base em distintas formas do laço social, a divisão entre centro e periferia como enquadramento das desigualdades regionais e a alternância entre contextos de hegemonia e de rivalidade entre núcleos de poder.

Nessa perspectiva, uma sociedade é um conjunto de seres humanos que mantém algum tipo de relação regular. Dentre as principais relações podemos mencionar as simbólicas, as econômicas e as coercitivas. Essa lista não é exaustiva, mas oferece uma base para entender a abrangência geográfica da sociedade. A violência é uma forma de relação pela qual coagimos ou protegemos os outros. Embora contraintuitiva, a ideia de que laços humanos não são exclusivamente pacíficos é central para entender as diferentes formas históricas de organização política. A economia é uma dessas formas de estabelecer relações. A organização da subsistência sempre foi coletiva, seja por prestações entre parentes ou entre súditos e um líder, seja por compra e venda em relações comerciais, do trabalho coordenado de caçadores e coletores ao complexo arranjo produtivo de cadeias de valor global. As relações simbólicas manifestam como partilhamos informações ou enquadramentos do mundo pela religião ou outras ideologias, como nos expressamos e usufruímos da cultura. Cabe apontar que essas diferenciações são apenas analíticas. A realidade é mais rica que a divisão abstrata entre esses três laços humanos, como nos lembra, por exemplo, a caracterização de Marcel Mauss (2003) sobre fatos sociais totais.

Mas o mundo não é dividido em diferentes países? Por que então não dizemos que vivemos em sociedades distintas? Não vivemos na sociedade brasileira, que é diferente da estadunidense, da indiana e de todas as outras? Esses recortes revelam apenas como nos organizamos politicamente e como se sedimentaram as relações coercitivas nos últimos séculos. Estados modernos, enquanto organizações políticas que reivindicam o monopólio da coerção legítima - na definição clássica weberiana -, servem como referência para as dinâmicas da violência interna (crime organizado, dissidência armada) e externa (guerras). Embora alguns estados logrem uma regulação bem-sucedida de boa parte da vida social em seu território, eles jamais constituem barreiras completas às relações econômicas ou simbólicas. As pessoas ainda cultivam seu gosto por bandas de heavy metal inglesas ou brasileiras no Irã, onde o estilo musical é proibido. O contrabando também segue uma prática exemplar da permeabilidade estatal. Guerras de escala global, desde o século XVIII, e a preocupação pós-Segunda Guerra com uma governança da segurança global em diferentes instâncias, ilustram como o estado moderno não demarca sociedades, mas constitui tão somente uma referência da rede de relações coercitivas. 
A fim de elucidar a história da sociedade global, é preciso ainda examinar duas dimensões subjacentes: primeiro, as transformações promovidas pela inovação técnica e institucional; e segundo, as relações assimétricas estabelecidas nesse processo.

As inovações técnicas e institucionais constituem a base das diferentes formas de organização social analisadas pelas Ciências Sociais. É uma questão central da disciplina, pensada por Marx, por exemplo, com base em seus sucessivos modos de produção (comunista primitivo, antigo, feudal, asiático e capitalismo) e em Parsons, com seu modelo evolutivo de sociedades primitivas, arcaicas intermediárias e modernas. Não apenas os aspectos técnicos são levados em consideração nesse processo. Seguindo Habermas (1983), a importância do aprendizado moral e normativo - e sua incorporação em instituições - é equivalente àquela do aprendizado científico e instrumental.

Até onde a evidencia arqueológica nos permite especular, todos os humanos conseguiam sua subsistência até 11 mil anos atrás com caça e coleta. Os grupos eram pequenos, em bandos de até 50 pessoas, unidos por laços de parentesco, sem chefia ou hierarquias duradouras e com separações muito básicas de atividades entre adultos / crianças e homens / mulheres. Num processo iterativo e experimental com a natureza ao longo de vários milênios, plantas e animais foram domesticados, por exemplo, em aproximadamente $8500 \mathrm{AEC}^{9}$ no Crescente Fértil ${ }^{10}$ e de 7500 AEC onde hoje é a China (Diamond, 1997:100). Junto aos animais domesticados, grupos de horticultores e posteriormente de agricultores (com plantios de maior extensão) alcançaram condições para se expandir demograficamente e se complexificar. Complexificação no sentido de especialização funcional: as pessoas deixam de desempenhar mais ou menos as mesmas atividades, grupos passam a se especializar no plantio e colheita, outros no transporte, outros na coerção e violência, outros na produção de utensílios, outros na religião e administração, etc. Politicamente, aparecem as hierarquias. Com base na generosidade, custeada frequentemente pelo usufruto de benefícios desiguais na comunidade, certas pessoas assumem um papel de maior destaque na coordenação de várias atividades (colheitas, festas, cerimônias). Essa estratificação política se institucionaliza em chefaturas permanentes em sociedades agrícolas mais complexas. No segundo e terceiro milênio antes da Era Comum, os impérios mesopotâmicos, egípcios e chineses construíram administrações centralizadas sob vastos territórios, com figuras de liderança institucionalizadas e hereditárias.

\footnotetext{
${ }^{9}$ Seguindo historiadores que trabalham com longas temporalidades, substituímos o uso de AC/DC (antes de Cristo / depois de Cristo) por antes da Era Comum (AEC) e Era Comum (EC). As datas continuam as mesmas, mas dispensam a referência à cristandade, expressão de uma experiência cultural apenas parcial e particular.

${ }^{10}$ Região da Afroeurásia que abrange do vale do Rio Nilo, passando pela Palestina, até a Mesopotâmia.
} 
Uma segunda dimensão básica da teoria do sistema mundo da longa duração está nas assimetrias instituídas no processo histórico. A expansão da rede de relações humanas envolve a criação de diferenças regionais em termos de poder militar, econômico e simbólico. Sempre existiu uma grande heterogeneidade de grupos humanos em contato uns com os outros. Grupos agrícolas e estatais, por exemplo, conviveram com horticultores e caçadores e coletores não estatais. No capitalismo global contemporâneo, por sua vez, também ainda existem grupos de caçadores e coletores ${ }^{11}$. A inovação técnica e institucional criou grupos sociais com diferentes capacidades econômicas, militares e ideológicas. Impérios agrícolas com amplas burocracias e divisão do trabalho contavam com uma demografia mais numerosa, produziam maiores excedentes econômicos e reuniam maior força militar. O contrário era o caso em grupos de caçadores e coletores e horticultores. Apesar das diferentes formas de vida, esses grupos não viviam isolados, mas sempre mantinham laços, mesmo que esporádicos.

Ao longo da história humana, as inovações técnicas e institucionais estabeleceram também diferenças regionais hierárquicas: centros e periferias dos sistemas sociais. Não se trata da formação de sociedades em distintos estágios de desenvolvimento. Há uma mesma sociedade na qual vários grupos mantêm laços simbólicos, econômicos e militares, com diferenças de poder de acordo com sua posição nesse sistema social. O entorno do império acadiano na mesopotâmia do terceiro milênio antes da era comum era habitado de modo periférico por grupos nômades: sua dinâmica econômica, militar e simbólica era subordinada e dependente do centro do império. Com subsistência relacionalmente mais precária, o comércio pontual e tentativas de saques nas fronteiras do império eram um elemento central de sua dinâmica política - bons chefes lideravam ataques bem-sucedidos - e simbólica - assombro diante de sua cultura letrada e divindades, acompanhado dos correspondentes ultrajes à cultura acadiana, quando o contexto permitia. Outros exemplos ilustram essa dinâmica centro-periferia: impérios chineses com relação a manchus e mongóis, romanos com relação a povos germânicos, os Tula com relação aos Mexica na Mesoamérica. Baseada no regime primário exportador, a dependência latinoamericana dos séculos XIX e XX - descortinada por cepalinos e dependentistas - seria mais uma expressão histórica de uma longa dinâmica da expansão geográfica das relações sociais geograficamente assimétricas.

Como podemos então examinar a evolução da geografia das relações sociais ao longo do tempo? Por milênios, grupos sociais locais e regionais permaneceram relativamente isolados, com conexões culturais e econômicas pontuais. Suas relações se expandiram até que, no século VI AEC, emergem três grandes sistemas sociais: o americano, o leste asiático e o central. O

\footnotetext{
${ }^{11}$ Como, por exemplo, o povo andamanês no oceano índico e os Pirahã. das margens do Rio Maici na floresta amazônica.
} 
sistema social americano permanece pouco conectado com os restantes até as invasões europeias a partir do final do século XV. O leste asiático engloba regiões que vão da Índia à Manchúria, enquanto o sistema chamado de central se refere às regiões que englobam a Europa, o norte da África e se estendem até o atual Irã. Esses dois sistemas mantêm laços culturais e de comércio relevantes. Sua intensificação produzirá um sistema afroeuroasiático unificado ${ }^{12}$. A partir do século XVI, a região europeia desse sistema - até então uma semi-periferia - inicia uma expansão que culmina na formação de um sistema social planetário e capitalista. É nesse sistema que vivemos hoje ${ }^{13}$.

A terceira dimensão básica da abordagem sistema-mundista para a longa duração envolve a estrutura do centro dos sistemas sociais. Há uma alternância entre conjunturas de hegemonia e de rivalidade. Essa questão se torna particularmente relevante no moderno sistema capitalista. Períodos nos quais um país dotado de maior poder militar e econômico, que organiza politicamente e lidera ideologicamente o sistema, desembocam em contextos de disputas pela posição hegemônica. Uma referência central nesse ponto é Arrighi (1996), que propõe uma sucessão de hegemonias desde o século XVII: dos Países Baixos para o Reino Unido, nos séculos XVIII e XIX, para, finalmente, os EUA, no século XX. Desde a década de 1970, os sinais do declínio da hegemonia estadunidense suscitam a reflexão sobre a transição para um momento de rivalidade, como discutido também por Arrighi (2008). A ascensão da China e a emergência na imprensa de termos como "guerra comercial" e "corrida tecnológica" sugerem a pertinência desse enquadramento. A guerra internacional das vacinas - disputa para influenciar a adoção de imunizantes desenvolvidos por um ou outro país - é mais um capítulo dessa conjuntura de rivalidade entre EUA e Ásia.

Para a sociologia, a dimensão cultural ou simbólica da constituição e reprodução dessas assimetrias entre centro e periferia merece destaque. Um exemplo no capitalismo planetário contemporâneo pode ser encontrado no papel de organismos internacionais, como o Banco Mundial, já mencionado anteriormente. Na leitura sistema-mundista, sua atuação encarna ideologias favoráveis à reprodução da liderança estadunidense. Sua concepção sobre as formas da superação da pobreza foca em responsabilidades individuais, com iniciativas que fomentam estruturas produtivas que não resolvem o problema da condição periférica. As assimetrias simbólicas do sistema mundo têm raízes profundas, definem questões raciais e organizam as escalas valorativas que depreciam sistematicamente formas de vida da periferia. Termos como

\footnotetext{
12 Para um resumo das formulações no âmbito da teoria do sistema mundo sobre a formação do sistema afroeuroasiático, ver Chase-Dunn e Hall (1997:149-186) e Grinin e Korotayev (2012).

${ }^{13}$ Sobre essa longa dinâmica de expansão e unificação dos sistemas sociais, ver o debate em Frank e Gills (1993).
} 
colonialidade do poder, proposto por Aníbal Quijano (2005), buscam dar conta dessa camada das complexidades globais.

\section{As epidemias na dinâmica social de longa duração}

A pandemia de covid-19 coloca desafios intrincados à sociologia. A teoria da longa duração do sistema mundo oferece uma perspectiva endógena das epidemias, com relação à dinâmica social (Chase-Dunn; Hall, 1997:114). Ao contrário de visões que a consideram como um fator externo, advindo de contingências biológicas, pode-se então entender surtos de doenças como parte da expansão e intensificação de laços sociais.

Sistemas sociais são grandes reservatórios epidemiológicos. O limite geográfico das epidemias equivale ao limite das relações humanas. A despeito da lentidão dos transportes prémodernos, uma doença infecciosa originada em um ponto de determinado sistema acaba se espalhando por toda sua extensão. Em um mundo onde não havia vacinas, as doenças matavam as pessoas suscetíveis, deixavam sequelas nos sobreviventes e, finalmente, poderiam não encontrar mais condições para a erupção de um surto. Com o efeito da imunidade e de condições favoráveis (aos humanos), as doenças ficam então latentes no sistema social afetado, raramente sendo erradicadas - como ilustra a reemergência recente do sarampo em vários países.

Surtos epidêmicos são tão antigos quanto a relação regular entre animais e grupos numerosos de humanos. Semelhantemente ao caso do coronavírus, outras epidemias ao longo da história humana derivam de zoonoses. Vírus ou bactérias se adaptam e são menos agressivos em determinados animais, coexistindo em equilíbrio com seu hospedeiro. Transmitidos a humanos, eles podem mutar, se reproduzir e causar doenças. Tal é o caso de doenças como varíola, sarampo, gripe, peste bubônica, entre outras. A domesticação de animais no contexto de formações sociais sedentárias foi a principal fonte de doenças infecciosas ao longo da história. As condições para o compartilhamento de eventuais patógenos realizam-se na proximidade com gado, porcos, aves, cães, gatos e cavalos, em habitações que pouco os separam de humanos. O vírus que causa o sarampo, por exemplo, tem origem em bois e vacas.

$\mathrm{Na}$ trajetória de expansão das relações entre humanos, doenças e epidemias foram marcantes na dinâmica social da antiguidade (McNeill, 1976). O vale do rio Yangtzé só foi consistentemente ocupado pelas forças da dinastia Han, constituindo as bases territoriais da civilização chinesa, após cinco séculos de esforço contra as doenças das regiões mais quentes ao sul. A maior fragmentação territorial e volatilidade política da Índia antiga pode ser lida como resultado das constantes vicissitudes sociais desencadeadas pela malária e pela dengue. No 
primeiro século da Era Comum, esses desenvolvimentos entre humanos e patógenos desembocaram em quatro reservatórios epidemiológicos: no Crescente Fértil ${ }^{14}$, no leste asiático, no subcontinente indiano e no mediterrâneo. A partir desse momento, o maior contato entre essas áreas - principalmente comercial, com a rota da seda - faz esses reservatórios transbordarem. Inicia-se um longo período de crises epidêmicas e de adaptação epidemiológica das populações que não somente equivale ao processo de articulação de um sistema social afroeuroasiático, mas também se relaciona com o declínio das civilizações da antiguidade. No império romano do ocidente, surtos nos primeiros séculos da Era Comum, como a peste antonina, podem ser considerados como um dos vetores relevantes de seu colapso.

As epidemias assumiram igualmente um papel central no surgimento da modernidade. A formação da sociedade planetária capitalista atual conta com pelo menos dois episódios, nos quais as doenças são fatores importantes: a Peste Negra na Europa do século XIV e o genocídio das populações americanas no contexto da invasão europeia do século XVI.

A Peste Negra, cujo patógeno é uma bactéria (Yersinia pestis) transmitida por pulgas, é um dos fenômenos históricos associados à emergência do capitalismo na Europa. A principal hipótese é que a doença teve origem no leste asiático e chegou à Europa por navios comerciais que traziam, além de suas cargas, ratos com a pulga transmissora. As estimativas são espetaculares e apontam a morte de $1 / 3$ à metade da população europeia durante o século XIV ${ }^{15}$. A economia de redistribuição e reciprocidade num quadro político de chefaturas fragmentadas territorialmente - o que a historiografia europeia convencionou como feudalismo - é gravemente afetada pela epidemia. Acelera-se então a transição a uma economia de mercado. A drástica redução do número de camponeses teria, por um lado, aumentado seu poder de barganha junto aos senhores locais. Pressionados a entregar mais trabalho e tributos, eles se revoltavam ou fugiam para cidades - para ganhar a vida de modo assalariado. Por outro lado, nesse contexto de crise das rendas de seus domínios, os senhores expandiram a comercialização da produção agrária, a fim de compensar as perdas dos rendimentos servis. A epidemia não foi fator único ou determinante na ampliação do papel do mercado na Europa e no surgimento do capitalismo planetário. No entanto, ela é seguramente um dos elementos relevantes no conjunto de suas causas (Chase-Dunn; Lerro, 2013:214; Anievas; Nişancıoğlu, 2015).

A invasão europeia das Américas é motivada justamente pelo impulso comercial da Europa e representa um momento chave na expansão do capitalismo e na constituição de um sistema social planetário. Iniciam-se relações culturais, econômicas e coercitivas que - apesar de

\footnotetext{
${ }^{14}$ Região da Afroeurásia que abrange do vale do Rio Nilo, passando pela Palestina, até a Mesopotâmia.

15 Embora o episódio mais famoso da Peste Bubônica na Europa tenha acontecido no século XIV, seus surtos continuaram até o começo do século XIX, de acordo com Snowden (2019).
} 
muito assimétricas - eliminam a divisão entre o mundo afroeuroasiático e o americano, além das barreiras entre as duas reservas epidemiológicas. A rápida ocupação e exploração econômica das Américas por europeus deve-se parcialmente a uma vantagem tecnológica de seus transportes e armamentos. Afinal, África e Ásia - regiões muito mais promissoras economicamente do que as Américas nesse contexto - são invadidas apenas no século XIX. Largamente excedidos em número, os europeus tiveram nas doenças a principal vantagem contra os habitantes das Américas. Varíola, sarampo, gripe e tifo matam 95\% dos cerca de 20 milhões de habitantes da região do Império Asteca em pouco mais de um século (Diamond, 1997). Na região onde hoje encontra-se o Brasil, $3 / 4$ da população originária desapareceu até o início do século XVII. A drástica redução dos povos nativos pelas doenças do sistema central permitiu que as forças europeias se impusessem militar e economicamente. A integração das Américas ao sistema afroeuroasiático funda então o sistema social planetário capitalista.

\section{Comentários finais: a pandemia na sociedade capitalista planetária do século XXI}

A abordagem mobilizada ao longo deste artigo oferece ferramentas sociológicas para a compreensão da dinâmica social que não somente dá ensejo à pandemia, como também se transforma a partir dela. Reforçamos agora algumas lições da teoria do sistema mundo sobre a experiência de um ano da emergência sanitária: a pandemia como crise endógena, a desigualdade global dessa vivência e a disputa por hegemonia que organiza alguns de seus contenciosos. As transformações sociais em curso, com a rivalidade por hegemonia entre EUA e Ásia, se inserem em um contexto que merece melhor especificação. No âmbito da sociedade global capitalista em que vivemos nos últimos dois séculos, a historiografia da economia política delimita, por exemplo, a existência de um capitalismo liberal do século XIX até o período entre as duas guerras mundiais do século XX. Emerge então um capitalismo organizado - e os graus de organização dependem da região, refletindo as assimetrias planetárias -, que é finalmente substituído pelo neoliberalismo financeirizado ${ }^{16}$ da virada do século XX para o XXI. Nesse último regime, o mercado avança tanto reformulando contextos onde suas forças foram restringidas ao longo do século XX - Europa e Américas - como onde antes ele era menos expressivo - China e sudeste asiático. Ademais, o ganho com crédito e especulação financeira tem concorrido ou suplantado o das atividades produtivas em vários espaços, impactando no potencial de crescimento econômico e na distribuição de renda dentro dos países. A subsistência se ordena por mecanismos de compra e venda, inclusive de recursos naturais, trabalho e dinheiro,

\footnotetext{
${ }^{16}$ Embora longo e deselegante, esse sobrenome do capitalismo contemporâneo tem a virtude de condensar suas principais características, como propõe, por exemplo, Epstein (2005).
} 
com efeitos disruptivos conhecidos e apontados por Karl Polanyi, por exemplo, para o liberalismo do século XIX.

A pandemia de covid-19 pode ser interpretada como consequência do avanço técnico e econômico, fazendo dialogar as teorias da modernidade tardia com a teoria do sistema mundo, quando a telescopamos para as últimas décadas. Seguindo a formulação de Ulrich Beck, o final do século XX no capitalismo planetário é caracterizado pela emergência de diferentes riscos supranacionais inerentes a esses avanços, quando os custos e ameaças da modernidade passam a superar seus benefícios em termos de afluência material e domínio sobre o mundo natural. Às vicissitudes da natureza se juntam também as indeterminações e perigos criados precisamente pelos avanços que deveriam os conter (Beck, 2011).

Dois aspectos do avanço técnico e econômico de nosso momento histórico estão relacionados a novos riscos epidemiológicos: a intensificação do extrativismo animal e a revolução da produção animal. Na China, por exemplo, a expansão capitalista, a maior densidade mercantil e o aumento do poder de compra de sua população estimulam a maior amplitude do extrativismo animal, criando as condições para a emergência de novas variantes de infecção respiratória humana. Origem da covid-19, o contato mais amplo e regular entre pangolins e humanos sucede nesse moderno quadro de extrativismo animal em maior escala e de riscos ascendentes no contato com animais silvestres ${ }^{17}$. Quanto às espécies domesticadas, o risco de novos patógenos vem dos métodos e escalas industriais de criação animal. A reunião de um grande número de animais, sua alteração e homogeneização genética e o manejo confinado em ambientes estressantes configuraram condições para o surgimento de focos da gripe aviária. Esse modelo de produção de alimentos em larga escala tem o potencial de fazer aparecer ainda muitas novas doenças similares (Wallace, 2016; Davis, 2020).

Não apenas a pandemia se torna inteligível como processo endógeno ao sistema mundo, mas também as diferentes experiências globais ganham sentido com base nessa perspectiva. Como ilustração da desigualdade entre países, introduzimos alguns casos de vida do Laos, Quênia e Reino Unido. Narramos esses casos sob a perspectiva dos regimes de subsistência, seguindo a formulação de Gough et al. (2004) e enfatizando a diferença nas matrizes institucionais às quais as pessoas recorrem para dirimir riscos. Cabe agora integra-los em uma perspectiva do sistema mundo.

A divisão entre centro e periferia no moderno sistema capitalista planetário é definida pela assimetria de poder econômico, militar e ideológico. Em um mundo enredado em cadeias globais de produção, a posição central é definida economicamente pela concentração das

\footnotetext{
${ }^{17}$ Ver a entrevista de Lopes (2020) com o biogeógrafo Jared Diamond.
} 
atividades mais sofisticadas tecnologicamente e com maior valor agregado por trabalhador. Se na formulação clássica cepalina (Cf. Prebisch, 1949) a indústria assumia um papel principal na construção dessas diferenças, as transformações econômicas das últimas décadas não apenas incluíram os serviços sofisticados no rol de atividades do centro, como também difundiram indústrias tradicionais (têxtis, por exemplo) para a periferia. Nessa linha, uma nova economia do desenvolvimento sensível à geografia econômica desigual incorpora uma perspectiva schumpeteriana da reprodução dessas assimetrias. Concentrando-se no centro, a inovação tecnológica cria mercados imperfeitos, nos quais rendas extraordinárias podem ser auferidas. Essas rendas se distribuem "aos capitalistas na forma de lucros maiores, aos trabalhadores na forma de salários maiores e aos governos na forma de impostos maiores” (Reinert, 2016:37). Com rendas menores de atividades em regime de concorrência perfeita, nos países periféricos, menores lucros se associam a menores investimentos em inovação, menores salários resultam no pauperismo (e em um fraco mercado interno), recursos fiscais reduzidos resultam em estados fracos, que logram desempenhar apenas parcialmente a monopolização da coerção legítima e seus papeis de agente redistributivo e do desenvolvimento.

Nessa interpretação, a maior vulnerabilidade do líder comunitário no Quênia e do pequeno artesão no Laos derivam da posição periférica dos países nos quais eles vivem. A reduzida densidade do mercado e a menor capacidade do estado tornam, nesses cenários, ineficazes essas importantes instâncias de proteção modernas, em um contexto de crise profunda. A menor vulnerabilidade da parteira britânica ilustra a segurança relativa das populações em países do centro, com mercados melhor estruturados e estados dotados de forte capacidade redistributiva. A pandemia é um choque que a atinge o planeta em meio à dinâmica de reprodução dessas assimetrias globais. Portanto, seus impactos serão muito distintos de acordo com essa geografia do sistema mundo.

Finalmente, a disputa por hegemonia no sistema mundo aparece nas disputas pela adoção de vacinas desenvolvidas nos EUA e países aliados ou em rivais geopolíticos da semiperiferia, tais como Rússia e China. O Brasil e a América Latina constituem um tabuleiro relevante e movimentado na crise da pandemia. Como consta no relatório 2020 do Departamento de Saúde do governo federal dos EUA, este país fez uso de "relações diplomáticas na região das Américas para mitigar os esforços de estados, incluindo Cuba, Venezuela e Rússia, que estão trabalhando para aumentar sua influência na região em detrimento da segurança dos EUA" (Secretary of Health and Human Services, s/d:48). Este órgão abriu pela primeira vez um escritório no Brasil, a fim de intensificar sua influência nas decisões sobre a vacina. O episódio do questionamento da vacina Sputnik V, de origem russa, pela Anvisa em abril de 2021 também pode ser entendido 
nesses termos, no âmbito de um país deflagrado federativamente, com o poder central em conflito com os estados não alinhados. A rivalidade por hegemonia no sistema mundo joga luz ainda sobre o sucesso parcial da iniciativa da OMS em coordenar um programa global de desenvolvimento e distribuição de vacinas que favorecesse países da periferia (COVAX).

Esse exame com base na teoria do sistema mundo da longa duração destaca então como uma pandemia endógena ao desenvolvimento do capitalismo planetário encontra populações mais vulneráveis na periferia, onde existe uma matriz institucional de proteção menos robusta, e cujos desdobramentos sanitários envolvem rivalidade hegemônica entre EUA e Ásia. Esse diagnóstico sugere algumas questões de pesquisa prementes. A crise da pandemia, dada a matriz institucional de proteção mais precária na periferia, aumentará as desigualdades globais nos próximos anos? A conjuntura de indeterminação favorecerá o declínio da hegemonia estadunidense, confirmando um cenário de forte rivalidade pela liderança do sistema mundo, ou se reforçará essa hegemonia? Uma vez que a pandemia está associada a intensificação da interdependência humana no capitalismo planetário, inaugurar-se-á um período de contínuas urgências sanitárias e de repetidos surtos epidêmicos? Ou, alternativamente, os avanços técnicos e o aumento do controle das populações reduzirão esses riscos?

\section{Referências}

ABU-LUGHOD, Janet L. (1989), Before European hegemony: the world system AD 1250-1350. New York, Oxford University Press.

AKNIN, Lara et al. (2021), "A Review and Response to the Early Mental Health and Neurological Consequences of the COVID-19 Pandemic". PsyArXiv [Consult. 20-04-2021]. Disponível em https://psyarxiv.com/zw93g/

ANIEVAS, Alexander; NIŞANCIOĞLU, Kerem (2015), How the West came to rule. London, Pluto Press.

ARENTI, W.; FILOMENO, F. (2007), "Economia política do moderno sistema mundial: as contribuições de Wallerstein, Braudel e Arrighi". Ensaios FEE. v. 28, n. 1, pp. 99-126 [Consult. 20-04-2021]. Disponível em https://revistas.dee.spgg.rs.gov.br/index.php/ensaios/article/view/2138

ARRIGHI, Giovanni (2008), Adam Smith em Pequim: origens e fundamentos do século XXI. São Paulo, Boitempo.

ARRIGHI, Giovanni (1996), O longo século XX: dinheiro, poder e as origens do nosso tempo. Rio de Janeiro, Contraponto Editora.

BECK, Ulrich (2011 [1986]), Sociedade de risco: rumo a uma outra modernidade. São Paulo, Editora 34.

BHAMBRA, Gurminder K. (2014), Connected sociologies. London, Bloomsbury Publishing.

BIELSCHOWSKY, R., TORRES, M. (2018), Desarrollo e igualdad: el pensamiento de la CEPAL en su séptimo decenio. Textos seleccionados del período 2008-2018. Santiago, CEPAL. 
CARDOSO, Adalberto (2013), Ensaios de sociologia do mercado de trabalho brasileiro. Rio de Janeiro, FGV.

CASTALDELLI-MAIA, J. M., MARZIALI, M. E., LU, Z. AND MARTINS, S. S. (2021), "Investigating the effect of national government physical distancing measures on depression and anxiety during the COVID-19 pandemic through meta-analysis and meta-regression," Psychological Medicine, pp. 1-13.

CECCHINI, Simone et al. (2015), Instrumentos de protección social: caminos latinoamericanos hacia la universalización. Santiago, CEPAL, pp. 32-42.

CHASE-DUNN, Christopher; HALL, Thomas D. (1997), Rise and demise: Comparing world systems. Boulder, Westview Press.

CHASE-DUNN, Christopher; LERRO, Bruce (2016), Social change: Globalization from the Stone Age to the present. London, Routledge.

CHERNILO, Daniel (2008), A social theory of the nation-state: The political forms of modernity beyond methodological nationalism. London, Routledge.

DAVIS, Mike (2020), The Monster Enters: COVID-19, Avian Flu and the Plagues of Capitalism. New York, OR Books.

DELANTY, Gerard (Ed.) (2021), Pandemics, Politics, and Society: Critical Perspectives on the Covid-19 Crisis. Berlin/Boston, de Gruyter.

DIAMOND, Jared (1997), Guns, germs and steel: a short history of everybody for the last 13,000 years. New York, W. W. Norton.

DUDBRIDGE, Glen (2018), "Reworking the World System Paradigm". Past \& Present, v. 238, n. suppl. 13, pp. 297-316.

EPSTEIN, Gerald A. (ed.) (2005), Financialization and the world economy. Cheltenham, Edward Elgar Publishing.

ERRA, Felipe Mendes (2020), "Perspectivas da história econômica global da baixa Idade Média". Esboços: histórias em contextos globais, v. 27, n. 44, pp. 17-37 [Consult. 20-04-2021]. Disponível em https://doi.org/10.5007/2175-7976.2020.e66839

ESPING-ANDERSEN, Gosta (1990), The three worlds of welfare capitalism. Princeton, Princeton University Press.

FRANK, Andre G.; GILLS, Barry K. (1993a), "The 5,000-year world system: An interdisciplinary introduction", in Frank, A. G.; Gills, B. K. (Orgs.), The world system: Five hundred years or five thousand, London, Routledge, pp. 3-55.

FRANK, Andre G.; GILLS, Barry K. (Orgs.) (1993b). The World System: The world system: 500 years or 5,000? London, Routledge.

GOUGH, Ian et al. (orgs.) (2004), Insecurity and welfare regimes in Asia, Africa and Latin America: Social policy in development contexts. Cambridge, Cambridge University Press.

GRININ, Leonid; KOROTAYEV, Andrey (2012), "The Afroeurasian World-System: Genesis, Transformations, Characteristics", in Babones, S.; Chase-Dunn, C. (eds.), Routledge Handbook of World-Systems Analysis. London-New York, Routledge, pp. 30-41. 
HABERMAS, Jürgen (1983), "Para a reconstrução do materialismo histórico", in Habermas, J. Para a reconstrução do materialismo histórico. São Paulo, Brasiliense.

HALL, Thomas D.; CHASE-DUNN, Christopher (1993), "The world-systems perspective and archaeology: Forward into the past”. Journal of Archaeological Research, v. 1, n. 2, pp. 121-143.

ILO (2017), World Social Protection Report 2017-19. Genebra, ILO.

ILO (2021), ILO Monitor: COVID-19 and the world of work. 7th edition. Genebra, ILO.

MATTHEWMAN, S.; HUPPATZ, K. (2020), “A sociology of Covid-19”. Journal of Sociology, v. 56, n. 4, pp. 675-683.

MAUSS, Marcel. (2003), "Ensaio sobre a dádiva”, in MAUSS, M. Sociologia e Antropologia. São Paulo, Cosac Naif.

MCNEILL, William. (1976), Plagues and peoples. Garden City, Anchor.

PLEYERS, Geoffrey (2021), A plea for global sociology in times of the coronavirus. ISA Digital Platform [Consult. 20-04-2021]. Disponível em https://www.isa-sociology.org/en/publications/isadigital-worlds/global-sociology-and-the-coronavirus

QUIJANO, Anibal (2005), "Colonialidade do poder, eurocentrismo e América Latina”, in: Lander, E. (Org.). A colonialidade do saber eurocentrismo e ciências sociais: perspectivas latino-americanas. Buenos Aires, CLACSO.

PIETERSE, Jan Nederveen; LIM, Haeran; KHONDKER, Habibul (Orgs.) (2021), Covid-19 and Governance: Crisis Reveals. Abingdon, Routledge.

REINERT, Erik. (2016), Como os países ricos ficaram ricos... e por que os países pobres continuam pobres. Rio de Janeiro, Contraponto.

RODRIGUES, Léo P.; COSTA, Everton G. da; GUEDES, Eduardo R. "Introdução: em tempos de pandemia... para um pós-epidêmico como oportunidade virtuosa". Simbiótica, Edição Especial, v. 7, n. $1, \quad$ pp. 1-10, 2020 [Consult. 20-05-2021]. Disponível em https://periodicos.ufes.br/simbiotica/article/view/30978

SECRETARY OF HEALTH AND HUMAN SERVICES. (s/d), 2020 Annual Report [Consult. 04-042021]. Disponível em https://www.hhs.gov/sites/default/files/2020-annual-report.pdf

STRAUSSFOGEL, Debra (1998), "How many world-systems? A contribution to the continuationist/transformationist debate". Review (Fernand Braudel Center), v. 11, n.1, pp. 1-28.

VIEIRA, Pedro A.; VIEIRA, Rosangela L.; FILOMENO, Felipe A. (Orgs) (2012), O Brasil e o capitalismo histórico: passado e presente na análise dos sistemas-mundo. São Paulo, Cultura Acadêmica Editora.

WALLACE, Rob (2016), Big farms make big flu: dispatches on influenza, agribusiness, and the nature of science. New York, NYU Press.

WALLERSTEIN, Immanuel (1974a), "The rise and future demise of the world capitalist system: Concepts for comparative analysis". Comparative studies in society and history, v. 16, n. 4, pp. 387415.

WALLERSTEIN, Immanuel (1974b), The modern world-system I. New York, Academic Press. 
WALLERSTEIN, Immanuel (1993), "World system versus world-systems", in Frank, A. G.; Gills, B. K. (orgs.), The 5,000-year world system: An interdisciplinary introduction. The world system: Five hundred years or five thousand, London, Routledge, pp. 292-296.

WANG, Yeli; KALA, Monica P.; JAFAR, Tazeen H. (2020), "Factors associated with psychological distress during the coronavirus disease 2019 (COVID-19) pandemic on the predominantly general population: A systematic review and meta-analysis". PloS one, v. 15, n. 12, pp. e0244630.

WOLF, Eric (2005), A Europa e os povos sem história. São Paulo, Edusp.

\section{Fontes de imprensa}

BANCO MUNDIAL. (2021), One Year Into The COVID-19 Pandemic, Six Stories That Inspire Hope. 10 de março de 2021, [Consult. 21-04-2021].

Disponível em https://www.worldbank.org/en/news/feature/2021/03/10/one-year-into-the-covid-19pandemic-six-stories-that-inspire-hope

GERKEN, Tom. (2021), Long Covid: 'I can't walk 10m without a rest'. BBC News, 18 de fevereiro de 2021, [Consult. 18-04-2021]. Disponível em https://www.bbc.com/news/uk-56113021

LOPES, Reinaldo José. Perigo são patógenos originados dos animais silvestres, diz Jared Diamond. Folha de São Paulo, Cotidiano, 13 de junho de 2020.

Disponível em: https://www1.folha.uol.com.br/cotidiano/2020/06/perigo-sao-patogenos-originadosdos-animais-silvestres-diz-jared-diamond.shtml 


\begin{abstract}
The article indicates lessons from the world system theory on some aspects of the crisis caused by the covid-19 pandemic. Based on coverage from newspapers, reports from international organizations, statistical data from 2020 and carrying out a bibliographic analysis of the theoretical framework, I advance three lessons on the global experience of a year of pandemic. First, the pandemic must be understood as an endogenous phenomenon to the dynamics of the capitalist world system. Second, global inequality must be an essential frame of reference for examining the different experiences engendered by the pandemic. Finally, the dispute for hegemony organizes some of the main disputes during the crisis, such as the rivalry over the adoption of different vaccines.
\end{abstract}

Keywords: world system theory; Covid-19; history; epidemics.

\title{
Resumen
}

El artículo señala lecciones de la teoría del sistema mundo sobre aspectos de la crisis causada por la pandemia del covid-19. Con base en material periodístico, informes de organismos internacionales, datos estadísticos del contexto del 2020 y un análisis bibliográfico de la constelación teórica antes mencionada, se proponen tres lecciones sobre la experiencia global de un año de pandemia. Primero, la pandemia debe entenderse como un fenómeno endógeno a la dinámica del sistema mundo capitalista. En segundo lugar, la desigualdad global debe ser un marco de referencia indispensable para examinar las diferentes experiencias engendradas por la pandemia. Finalmente, la disputa por la hegemonía organiza algunos de los principales litigios de la coyuntura, como la rivalidad por la adopción de distintas vacunas.

Palabras clave: teoría del sistema-mundo; Covid-19; historia; epidemias. 